\title{
Rates and determinants of exclusive breastfeeding in first 6 months among women in Nova Scotia: a population-based cohort study
}

\author{
Catherine R.L. Brown MSc, Linda Dodds PhD, Rebecca Attenborough RN MN, Janet Bryanton RN PhD, \\ Annette Elliott Rose RN MN, Gordon Flowerdew PhD, Donald Langille MD MHSc, \\ Leeanne Lauzon RN MSc, Sonia Semenic RN PhD
}

\section{Abstract}

Background: Despite compelling evidence that exclusive breastfeeding for the first 6 months of life provides important health benefits to both mothers and their infants, most mothers do not follow this practice. We conducted a study to identify predictors of early cessation of exclusive breastfeeding (before 6 months after delivery).

Methods: For this population-based longitudinal cohort study, we linked data from a perinatal database and a public health database for infants born between 2006 and 2009 in 2 regions in the province of Nova Scotia, Canada. The cohort was followed from the mother's first prenatal visit until her infant was 6 months old. Hazard ratios (HRs) for early cessation of exclusive breastfeeding were determined through Cox proportional hazards regression modelling.

Results: Overall, 64.1\% (2907/4533) of the mothers in the cohort initiated breastfeeding. Only 10.4\% (413/3957) exclusively breastfed for the recommended 6 months. The largest drop in exclusive breastfeeding occurred within the first 6 weeks after birth. Among the mothers who initiated breastfeeding, significant predictors of early cessation of exclusive breastfeeding identified by multivariable modelling included less than high school education (HR 1.66, 95\% confidence interval [Cl] 1.35-2.04), lowest neighbourhood income quintile (HR 1.35, 95\% Cl 1.13-1.60), single motherhood (HR 1.24, 95\% Cl 1.10-1.41), prepregnancy obesity (HR 1.43, 95\% Cl 1.231.65), smoking throughout pregnancy ( $\mathrm{HR} 1.39,95 \% \mathrm{Cl} 1.21-1.60)$, no early breast contact by the infant $(<1$ hour after birth) (HR $1.44,95 \% \mathrm{Cl} 1.29-1.62)$ and no intention to breastfeed (HR 1.78, 95\% Cl 1.44-2.16).

Interpretation: We found that most predictors of early cessation of breastfeeding were intertwined with social determinants of health. However, we identified potentially modifiable risk factors. Providing opportunities for early breast contact by the infant and continued efforts in smoking cessation and obesity reduction may contribute to a longer duration of exclusive breastfeeding.

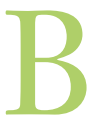

reast milk is the best food source for optimal infant growth and development. Research consistently offers compelling evidence that exclusive breastfeeding provides health benefits to both infant and mother throughout their lifespans, thereby substantially reducing health care costs. ${ }^{1,2}$ The World Health Organization and Health Canada recommend that infants be exclusively breastfed for the first 6 months of life. ${ }^{3,4}$ Exclusive breastfeeding involves offering only breast milk and any necessary vitamins, minerals and medicine, while excluding all other liquids, breast-milk substitutes and solid foods. ${ }^{4}$ Data from national cross-sectional surveys suggest that, although nearly $90.3 \%$ of Canadian mothers initiate breastfeeding, less than $25 \%$ exclusively breastfeed their infant for the recommended 6 months. ${ }^{5}$ At $9.6 \%$, the rate of exclusive breastfeeding in the province of Nova Scotia, Canada, is even lower. ${ }^{5}$

Not following the recommended breastfeeding practices places mothers and infants at increased risk of ill health and is associated with substantial economic costs. ${ }^{6}$ With such a low percentage of mothers in Nova Scotia and Canada who follow the recommendation for exclusive breastfeeding for 6 months, the challenge for health care professionals is to find interventions that aim to bridge the gap between current and recommended practices. Since the Health Canada recommendation was introduced in 2004, few Canadian longitudinal studies have been conducted on the factors that contribute to increased rates of breastfeeding duration and exclusivity. Further, existing Canadian cohort studies of breastfeeding practices were limited to

Competing interests: None declared.

This article has been peer reviewed.

Correspondence to: Linda Dodds, L.Dodds@dal.ca

CMAJ Open 2013.DOI:10.9778/cmajo.20120011 
subpopulations such as low-income mothers and single urban centres. ${ }^{7-10}$ By understanding the factors associated with positive breastfeeding practices, health care providers will be better equipped to promote and support breastfeeding. We conducted a study involving mother-infant pairs in the province of Nova Scotia, Canada, to identify predictors of early cessation of exclusive breastfeeding (before 6 months after delivery).

\section{Methods}

\section{Study design}

For this population-based longitudinal cohort study, we used data from the Nova Scotia Atlee Perinatal Database and the Healthy Beginnings public health database. Unique within the province, public health nurses in 2 district health authorities - Cape Breton District Health Authority and Guysborough Antigonish Strait Health Authority - collected additional information on breastfeeding patterns from all mothers for the province's public health database. This information included the mother's self-reported breastfeeding status collected prospectively at the time of hospital discharge and at 5 follow-up assessments (at 1 and 6 weeks, and 2, 4 and 6 months after birth). The nurses collected the data on breastfeeding through telephone or face-to-face interviews.

Information on the duration of breastfeeding in the public health database was linked with data in the Nova Scotia Atlee Perinatal Database. The perinatal database began in 1988 and includes data on all hospital deliveries in the province. It contains extensive maternal, prenatal, labour, birth and in-hospital breastfeeding information for all pregnancies that resulted in the birth of an infant of more than 20 weeks' gestational age or more than $500 \mathrm{~g}$. Ongoing data-quality activities are conducted by the Reproductive Care Program of Nova Scotia, and the database has been validated against external databases. ${ }^{11,12}$

This study received ethics approval from the Research Ethics Board of the IWK Health Centre, as well as the Research Ethics Boards of the Cape Breton District Health Authority and the Guysborough Antigonish Strait Health Authority.

\section{Study population}

We included all live newborns in Nova Scotia whose mother resided in the Cape Breton District Health Authority or the Guysborough Antigonish Strait Health Authority between Jan. 1, 2006, and Dec. 31, 2009. Together, these 2 district health authorities represent about $17 \%$ of the province's births. ${ }^{13}$ Multiple births were excluded from the analysis because of their unique feeding challenges. A deterministic record linkage, based primarily on the unique health card number assigned to all residents of Nova Scotia, was used to link data in the 2 databases. We excluded records from the public health database that did not have a corresponding birth record in the perinatal database.

\section{Outcome measures}

We followed Labbok and Krasovec's definition of "almost exclusive breastfeeding” for exclusive breastfeeding (i.e., allowing for occasional tastes of other liquids, vitamins or medicines, etc.). ${ }^{14}$ Infants were considered exclusively breastfed if the mother indicated at follow-up that she provided her infant only breast milk since birth. Feeding was considered supplementary if the mother indicated that she supplemented breast milk with formula, cow's milk, water or other foods. Any breastfeeding was defined as feeding that was either exclusive or supplementary.

The duration of exclusive breastfeeding was defined as the time between birth (where the mother reported exclusive breastfeeding) and the first follow-up visit when supplementary feeding was reported. To derive the duration of breastfeeding, we used interval censoring of follow-up data using midpoint imputation. For example, if a woman reported breastfeeding at 2 months, but had stopped by 4 months, the derived duration would be 3 months. If the mother was lost to follow-up (i.e., breastfeeding initiation was confirmed and some information on breastfeeding duration was available, but there was no information on when a mother stopped breastfeeding), the duration of breastfeeding was determined to be the time point of the last follow-up where a woman reported breastfeeding. When a breastfeeding assessment was late, data were collected as though the assessment had been done at the expected follow-up date. Thus, breastfeeding duration was based on the prescribed follow-up time points (at 1 and 6 weeks, and 2, 4 and 6 months). For mother-infant pairs who never initiated breastfeeding, the duration was recorded as 0 months.

We included 25 potential predictors of exclusive breastfeeding derived from the literature in our analysis (Table 1)..$^{7-10,15-17}$ We linked the mothers' postal codes to Canadian census data to estimate neighbourhood income quintiles. Location of residence was dichotomized into urban and rural with the use of the postal codes (postal codes for rural residences had zero as the second digit). No Canadian standards for body weight classification exist for females less than 18 years old; however, the Institute of Medicine suggests that a prepregnancy body mass index (BMI) for adolescents can be adequately categorized using adult cutoff values. ${ }^{18}$ Therefore, for women of all ages, the prepregnancy BMI was derived using the formula of prepregnancy weight divided by height squared. We classified this continuous variable as underweight, normal, overweight or obese, following the Canadian Guidelines for Body Weight Classification in Adults. ${ }^{19}$ Maternal smoking status was classified as "nonsmoker" (did not smoke at any time during pregnancy), "quit smoking during pregnancy" (smoked at least 1 cigarette before pregnancy or at the first prenatal visit but had quit by the time of admission for delivery) and "smoker at time of admission to hospital for delivery" (smoked at least 1 cigarette at admission).

\section{Statistical analysis}

We performed a Kaplan-Meier survival analysis for all predictor variables. Survival curves were stratified by each level of a predictor, and differences in the curves were tested by a logrank test of equality across strata. The curves were also visually examined for violation of the proportionality assumption. We used a Cox proportional hazards regression model to 
Table 1: Potential predictors of exclusive breastfeeding included in analysis of factors associated with duration of exclusive breastfeeding ${ }^{7-10,15-19}$

\begin{tabular}{|c|c|}
\hline Factor & Description \\
\hline Birth year & Infant's year of birth \\
\hline Maternal age & Mother's age at time of delivery \\
\hline Maternal education & Mother's highest level of education \\
\hline Marital status & Marital status at time of delivery \\
\hline $\begin{array}{l}\text { Location of } \\
\text { residence }\end{array}$ & Urban or rural residence \\
\hline $\begin{array}{l}\text { District health } \\
\text { authority }\end{array}$ & $\begin{array}{l}\text { Residence in Cape Breton District Health } \\
\text { Authority or Guysborough Antigonish } \\
\text { Strait Health Authority }\end{array}$ \\
\hline County of residence & $\begin{array}{l}\text { Residence in Antigonish, Cape Breton, } \\
\text { Guysborough, Inverness, Richmond or } \\
\text { Victoria County }\end{array}$ \\
\hline Income quintile & Neighbourhood income quintile \\
\hline Prepregnancy BMI & $\begin{array}{l}\text { From self-reported weight and height at } \\
\text { first prenatal visit; classified as } \\
\text { underweight, normal weight, overweight } \\
\text { or obese (Health Canada criteria }{ }^{19} \text { ) }\end{array}$ \\
\hline Smoking status & $\begin{array}{l}\text { Nonsmoker during pregnancy, quit } \\
\text { smoking during pregnancy or smoker at } \\
\text { admission for delivery }\end{array}$ \\
\hline Parity & Primiparous or multiparous \\
\hline Prenatal education & $\begin{array}{l}\text { Whether mother received prenatal } \\
\text { education }\end{array}$ \\
\hline $\begin{array}{l}\text { Folic acid } \\
\text { supplementation } \\
\text { before conception }\end{array}$ & $\begin{array}{l}\text { Whether mother took folic acid } \\
\text { supplements before conception }\end{array}$ \\
\hline $\begin{array}{l}\text { Health condition } \\
\text { during pregnancy }\end{array}$ & $\begin{array}{l}\text { Whether mother experienced at least one } \\
\text { of diabetes, hypertension or hyperemesis } \\
\text { gravidarum }\end{array}$ \\
\hline $\begin{array}{l}\text { Gestational } \\
\text { weight gain }\end{array}$ & $\begin{array}{l}\text { From prepregnancy BMI and gestational } \\
\text { weight gain; classified as suboptimal, } \\
\text { optimal or excessive (Institute of } \\
\text { Medicine criteria }{ }^{18} \text { ) }\end{array}$ \\
\hline Type of labour & $\begin{array}{l}\text { Spontaneous, induction of labour or no } \\
\text { labour }\end{array}$ \\
\hline Mode of delivery & Vaginal or cesarean delivery \\
\hline Perineal tear & $\begin{array}{l}\text { Whether mother experienced third- or } \\
\text { fourth-degree lacerations }\end{array}$ \\
\hline Epidural analgesia & $\begin{array}{l}\text { Whether mother received an epidural } \\
\text { during labour }\end{array}$ \\
\hline Gestational age & $\begin{array}{l}\text { Preterm }(<37 \text { weeks) or term } \\
\text { ( } \geq 37 \text { weeks) birth }\end{array}$ \\
\hline Infant birth weight & $<2500 \mathrm{~g}$ or $\geq 2500 \mathrm{~g}$ \\
\hline $\begin{array}{l}\text { Admittance to } \\
\text { special care nursery }\end{array}$ & $\begin{array}{l}\text { Whether infant was admitted to a special } \\
\text { care nursery }\end{array}$ \\
\hline Infant anomaly & $\begin{array}{l}\text { Presence of a major anomaly in infant } \\
\text { (e.g., Down syndrome, congenital heart } \\
\text { disease, cleft palate) }\end{array}$ \\
\hline $\begin{array}{l}\text { Intention to } \\
\text { breastfeed }\end{array}$ & $\begin{array}{l}\text { Whether mother intended to breastfeed; } \\
\text { information collected at prenatal visit or } \\
\text { admission for delivery }\end{array}$ \\
\hline Early breast contact & $\begin{array}{l}\text { Whether infant had direct contact with } \\
\text { mother's breast within } 1 \text { hour after birth }\end{array}$ \\
\hline
\end{tabular}

determine hazard ratios (HRs) to estimate the instantaneous relative risk of early cessation of exclusive breastfeeding. All predictive variables with an unadjusted test of equality of $p<0.1$ were included in the model. The model was built using backward modelling. Hazard ratios and associated 95\% confidence intervals (CIs) were calculated, and final predictors were considered significant using the likelihood ratio test. Ties were accounted for with use of the exact method. Eight of the predictive variables had missing values for more than $10 \%$ of the participants. For these variables, a dummy "missing" category was created.

All analyses with one exception were conducted with the use of SAS version 9.1. The Kaplan-Meier survival curves were plotted in SPSS 16.0.

\section{Results}

Of the 5353 mother-infant pairs available in the public health database, 4533 were included in the cohort (Figure 1). Among the 820 excluded pairs, 681 were unable to be linked to data in the perinatal database, and 139 were multiple births. For the regression model on exclusive breastfeeding, we included 2639 of the 2907 mothers who initiated breastfeeding; this model included 576 mothers who were censored because of incomplete follow-up for exclusive breastfeeding but excluded 268 mothers with incomplete data on predictor variables.

Overall, 2907 (64.1\%, 95\% CI 62.7\%-65.5\%) of the 4533 mothers initiated breastfeeding. Compared with mothers who did not initiate breastfeeding, mothers who initiated breastfeeding tended to be older and better educated and more likely

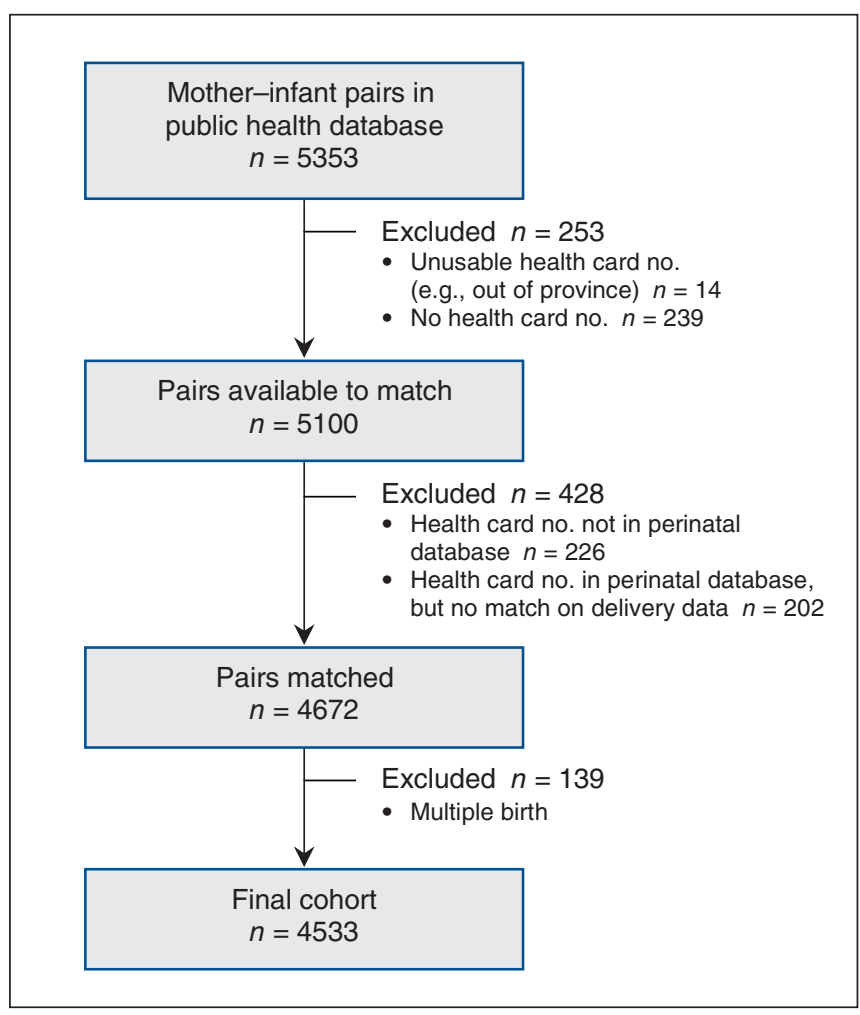

Figure 1: Selection of mother-infant pairs for the study. 


\section{OPEN}

Research

to be nonsmokers, married or in a common-law relationship, and to report an intention to breastfeed (Table 2). Obese mothers were as likely as normal-weight mothers to have an intention to breastfeed (69\% and $72 \%$, respectively) and to initiate breastfeeding (64\% and 66\%, respectively) (data not shown). The percentage of mothers who initiated breastfeeding increased significantly, from $60.5 \%$ in 2006 to $66.9 \%$ in $2009(p=0.001)$. At 6 weeks, 1427 (33.6\%, 95\% CI 32.2\%$35.0 \%)$ of 4247 mothers available for follow-up were exclusively breastfeeding their infant. At 6 months, this number dropped substantially to 413 (10.4\%, 95\% CI 9.5\%-11.4\%) of 3957 mothers available for follow-up. There was little variation in the rates of exclusive breastfeeding at 6 months between 2006 (10.7\%) and 2009 (8.9\%). Figure 2 shows the KaplanMeier curve for the duration of exclusive breastfeeding among the 2907 mothers who initiated breastfeeding. By 6 weeks, more than $40 \%$ of women had ceased exclusive breastfeeding.

Of the 25 factors evaluated, all but 4 (urban v. rural residence, prenatal education, type of labour and perineal tears) were associated with duration of exclusive breastfeeding at the

\begin{tabular}{|c|c|c|c|}
\hline \multirow[b]{2}{*}{ Characteristic } & \multicolumn{3}{|c|}{ No. (\%) of women* } \\
\hline & $\begin{array}{c}\text { All } \\
n=4533\end{array}$ & $\begin{array}{c}\text { Initiated } \\
\text { breastfeeding } \\
n=2907\end{array}$ & $\begin{array}{c}\text { Did not initiate } \\
\text { breastfeeding } \\
\quad n=1626\end{array}$ \\
\hline \multicolumn{4}{|l|}{ Age, yr } \\
\hline$<20$ & $326 \quad(7.2)$ & $143 \quad(4.9)$ & $183(11.3)$ \\
\hline $20-24$ & $961(21.2)$ & $548(18.9)$ & $413(25.4)$ \\
\hline 25-29 & $1333(29.4)$ & $864(29.7)$ & $469(28.8)$ \\
\hline $30-34$ & 1278 (28.2) & $899(30.9)$ & $379(23.3)$ \\
\hline$\geq 35$ & $635(14.0)$ & $453(15.6)$ & $182(11.2)$ \\
\hline \multicolumn{4}{|l|}{ Education } \\
\hline Less than high school & $472(12.3)$ & $188 \quad(7.5)$ & $284(21.3)$ \\
\hline High school diploma & 1223 (31.8) & $671(26.8)$ & $552(41.4)$ \\
\hline College diploma & $836(21.8)$ & $571(22.8)$ & $265(19.9)$ \\
\hline University degree & $1309(34.1)$ & $1075(42.9)$ & $234(17.5)$ \\
\hline \multicolumn{4}{|l|}{ Marital status } \\
\hline Single† & $1328(36.3)$ & 707 (29.2) & $621(50.2)$ \\
\hline Married & $2332(63.7)$ & $1717(70.8)$ & $615(49.8)$ \\
\hline \multicolumn{4}{|l|}{ Prepregnancy BMI } \\
\hline Underweight & $128(4.5)$ & $69 \quad(3.7)$ & $59 \quad(6.1)$ \\
\hline Normal weight & $1327(46.9)$ & $877(47.2)$ & $450(46.3)$ \\
\hline Overweight & $685(24.2)$ & $474(25.5)$ & $211(21.7)$ \\
\hline Obese & $689(24.4)$ & $438(23.6)$ & $251(25.9)$ \\
\hline \multicolumn{4}{|l|}{ Smoking status } \\
\hline Nonsmoker during pregnancy & $2831(67.0)$ & $2035(75.2)$ & $796(28.1)$ \\
\hline Quit during pregnancy & $352(8.3)$ & $234 \quad(8.6)$ & $118(7.8)$ \\
\hline Smoker at admission for delivery & $1040(24.6)$ & $438(16.2)$ & $602(39.7)$ \\
\hline Primiparous & $1889(41.7)$ & $1319(45.4)$ & $570(35.1)$ \\
\hline Folic acid supplementation before conception & $965(34.4)$ & $743(40.7)$ & $222(22.7)$ \\
\hline \multicolumn{4}{|l|}{ Mode of delivery } \\
\hline Cesarean & $1245(27.5)$ & $813(28.0)$ & $432(26.6)$ \\
\hline Vaginal & $3288(72.5)$ & $2094(72.0)$ & $1194(73.4)$ \\
\hline \multicolumn{4}{|l|}{ Intention to breastfeed } \\
\hline Yes & $2800(69.3)$ & $2541(94.6)$ & $259(19.1)$ \\
\hline No & $1243(30.7)$ & $145(5.4)$ & $1098(80.9)$ \\
\hline Early breast contact (within $1 \mathrm{~h}$ after birth) & 1140 (39.9) & $1107(52.1)$ & $33 \quad(4.5)$ \\
\hline $\begin{array}{l}\text { Note: } \mathrm{BMI}=\text { body mass index. } \\
{ }^{*} \text { Denominators for percentages do not include missing va } \\
\text { †Includes single, divorced, widowed and separated moth }\end{array}$ & & & \\
\hline
\end{tabular}


$p<0.1$ level of significance in the univariable analysis. After adjustment in the proportional hazards model, 9 risk factors were found to be independently associated with early cessation of exclusive breastfeeding (Table 3): lower level of education, lower neighbourhood income quintile, single motherhood, prepregnancy obesity, smoking throughout pregnancy, no folic acid supplementation before conception, primiparous mothers, no breast contact within 1 hour after birth, and no intention to breastfeed. The model was also adjusted for district health authority.

Unadjusted Kaplan-Meier curves for smoking status and prepregnancy BMI are presented in Figures 3 and 4. Clear gradients are seen across the 6-month period between levels of each factor. As well, these figures show that, among the mothers who initiated breastfeeding, the rates dropped more quickly in the first 6 weeks than in the remaining 4 months.

\section{Interpretation}

Although $64.1 \%$ of 4533 mothers in our study cohort initiated breastfeeding, only $10.4 \%$ were exclusively breastfeeding at 6 months. Because nearly half of the mothers stopped breastfeeding within the first 6 weeks after birth, this period represents a critical intervention window for supporting breastfeeding among mothers. Most of the predictors of exclusive breastfeeding identified in our study are intertwined with social determinants of health; however, we identified 4 potentially modifiable risk factors: prepregnancy obesity, smoking during pregnancy, no intention to breastfeed and no early breast contact by the infant. Interestingly, most factors related to the delivery and to the infant's health, including mode of delivery, receipt of epidural analgesia, infant's gestational age and weight, and admittance to a special care nursery, were not associated with the duration of exclusive breastfeeding.

The percentage of women who initiated breastfeeding in our study $(64.1 \%)$ is considerably lower than the national average $(90.3 \%) .{ }^{5}$ However, the percentage of those who continued to breastfeed exclusively for 6 months $(10.4 \%)$ is similar to the national average (14.4\%). In Canada, a clear geographic gradient exists: exclusive breastfeeding at 6 months is highest in western Canada and lowest in the Atlantic Provinces. ${ }^{16}$ We found a strong association between early cessation of exclusive breastfeeding and disparities in social determinants of health. Most Canadian studies corroborate this association between poorer breastfeeding practices and lower level of maternal education, single motherhood, lower income and location of residence..$^{7-10,15,16}$

As one of the potentially modifiable risk factors identified in our study, having no intention to breastfeed is an obvious risk factor associated with early cessation of exclusive breastfeeding and was reported by about $30 \%$ of the mothers in our study. Few interventional studies that aim to increase breastfeeding intention have been published; however, the limited available research suggests that educational interventions are more effective if focused on improving maternal self-efficacy than on enhancing knowledge. ${ }^{20}$ Moreover, less than one-half of the mother-infant pairs in the cohort had breast contact within 1 hour after birth, which was the variable in the data-

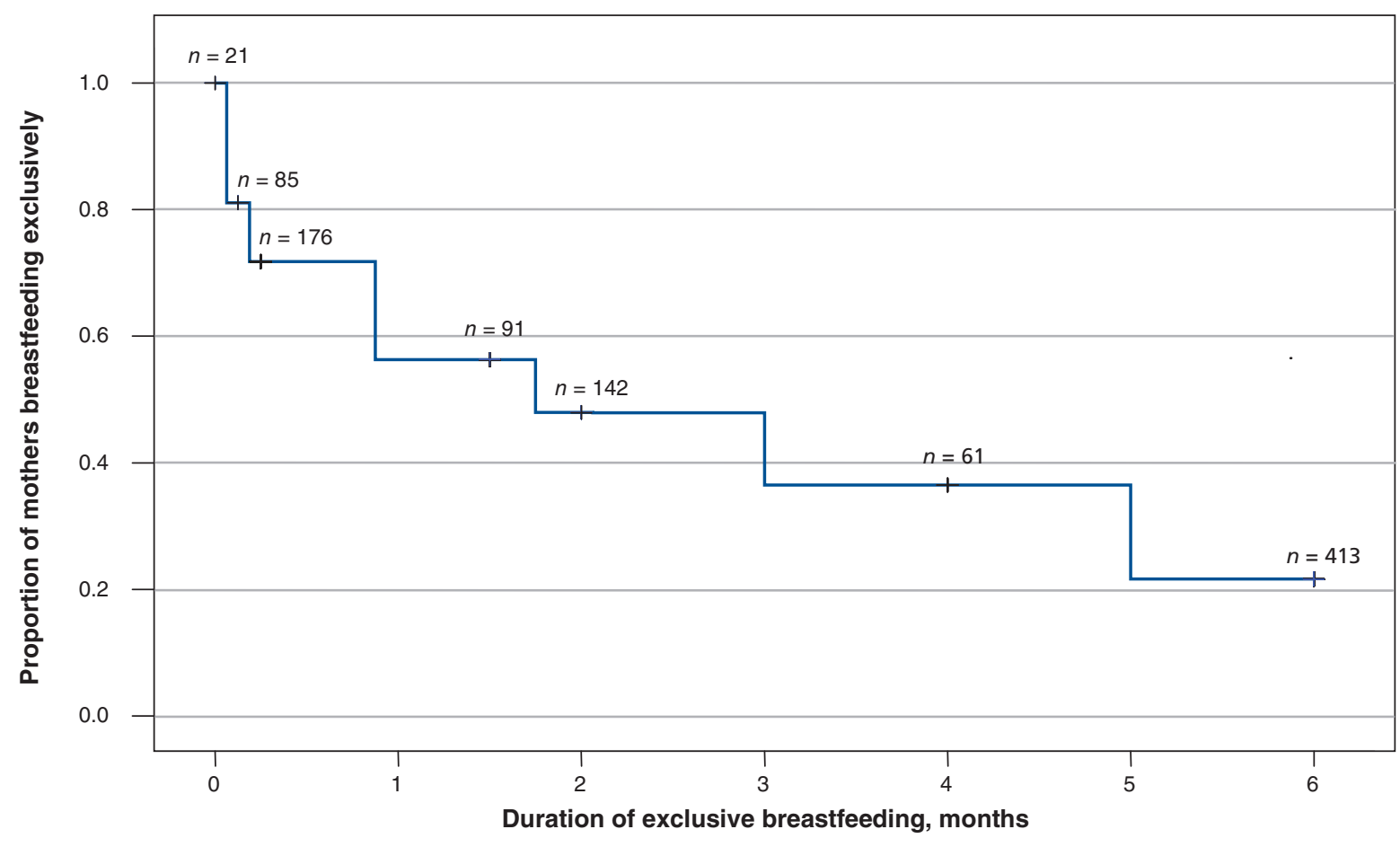

Figure 2: Kaplan-Meier curve of duration of exclusive breastfeeding in first 6 months after birth among 2907 mothers who initiated breastfeeding. $+=$ number of mothers censored at each point. 


\section{OPEN}

Research

base that closely resembled early skin-to-skin contact. Early skin-to-skin contact between a mother and her infant promotes bonding and initiation of breastfeeding, and it is one of the steps of the World Health Organization-UNICEF BabyFriendly Hospital Initiative, ${ }^{21}$ an intervention shown to increase both breastfeeding initiation and the duration of exclusive breastfeeding. ${ }^{22}$ No hospitals in Nova Scotia were designated as baby friendly throughout the study's duration, which probably contributed to the low proportion of mothers who engaged in early breast contact with their infants.

Why early cessation of exclusive breastfeeding was associated with smoking and obesity is not fully understood. These

\begin{tabular}{|c|c|c|c|}
\hline Variable & No. of mothers* & Adjusted HR† (95\% Cl) & $p$ value \\
\hline \multicolumn{4}{|l|}{ Education } \\
\hline Less than high school & 174 & $1.66(1.35-2.04)$ & \multirow{4}{*}{$<0.001$} \\
\hline High school graduate & 619 & $1.35(1.18-1.54)$ & \\
\hline College diploma & 509 & $1.25(1.08-1.43)$ & \\
\hline University degree & 969 & 1.00 (ref) & \\
\hline \multicolumn{4}{|l|}{ Neighbourhood income quintile } \\
\hline Highest & 654 & 1.00 (ref) & \multirow{5}{*}{$<0.001$} \\
\hline Upper-middle & 520 & $1.33(1.14-1.55)$ & \\
\hline Middle & 584 & $1.38(1.19-1.59)$ & \\
\hline Lower-middle & 541 & $1.27(1.10-1.48)$ & \\
\hline Lowest & 340 & $1.35(1.13-1.60)$ & \\
\hline \multicolumn{4}{|l|}{ Marital status } \\
\hline Married or common-law & 1563 & 1.00 (ref) & \multirow{2}{*}{0.001} \\
\hline Single, divorced, widowed or separated & 654 & $1.24(1.10-1.41)$ & \\
\hline \multicolumn{4}{|l|}{ Prepregnancy BMI } \\
\hline Underweight & 65 & $0.91(0.66-1.23)$ & \multirow{4}{*}{0.001} \\
\hline Normal & 808 & 1.00 (ref) & \\
\hline Overweight & 441 & $1.12(0.97-1.30)$ & \\
\hline Obese & 410 & $1.43(1.23-1.65)$ & \\
\hline \multicolumn{4}{|l|}{ Smoking status during pregnancy } \\
\hline Nonsmoker during pregnancy & 1982 & 1.00 (ref) & \multirow{3}{*}{$<0.001$} \\
\hline Quit during pregnancy & 227 & $1.09(0.92-1.29)$ & \\
\hline Smoker at admission for delivery & 430 & $1.39(1.21-1.60)$ & \\
\hline \multicolumn{4}{|l|}{ Parity } \\
\hline Primiparous & 1202 & 1.00 (ref) & \multirow{2}{*}{$<0.001$} \\
\hline Multiparous & 1437 & $0.76(0.69-0.84)$ & \\
\hline \multicolumn{4}{|l|}{$\begin{array}{l}\text { Folic acid supplementation before } \\
\text { conception }\end{array}$} \\
\hline Yes & 708 & 1.00 (ref) & \multirow{2}{*}{0.04} \\
\hline No & 1025 & $1.15(1.01-1.30)$ & \\
\hline \multicolumn{4}{|l|}{ Intention to breastfeed } \\
\hline Yes & 2319 & 1.00 (ref) & \multirow{2}{*}{$<0.001$} \\
\hline No & 136 & $1.78(1.44-2.16)$ & \\
\hline \multicolumn{4}{|l|}{ Early breast contact ( $<1 \mathrm{~h}$ after birth) } \\
\hline Yes & 1007 & 1.00 (ref) & \multirow{2}{*}{$<0.001$} \\
\hline No & 917 & $1.44(1.29-1.62)$ & \\
\hline $\begin{array}{l}\text { Note: } \mathrm{BMI}=\text { body mass index, } \mathrm{Cl}=\text { confidence inter } \\
{ }^{*} \text { The total number of women who initiated breastfee } \\
\text { status and district health authority. } \\
\text { †Adjusted for factors listed in the table, as well as th } \\
\text { prepregnancy BMI, prepregnancy folic acid supplen } \\
\text { but adjusted HRs are not shown. }\end{array}$ & $\begin{array}{l}\text { R = hazard ratio, ref } \\
\text { was } 2907 \text {, but this ana } \\
\text { ther's district health at } \\
\text { tion, breast contact wit }\end{array}$ & $\begin{array}{l}\text { ce category. } \\
\text { luded } 268 \text { women who had miss } \\
\text { Missing" categories for maternal } \\
\text { ur, and intention to breastfeed w }\end{array}$ & $\begin{array}{l}\text { s for smoking } \\
\text { n, marital stat } \\
\text { led in the mod }\end{array}$ \\
\hline
\end{tabular}




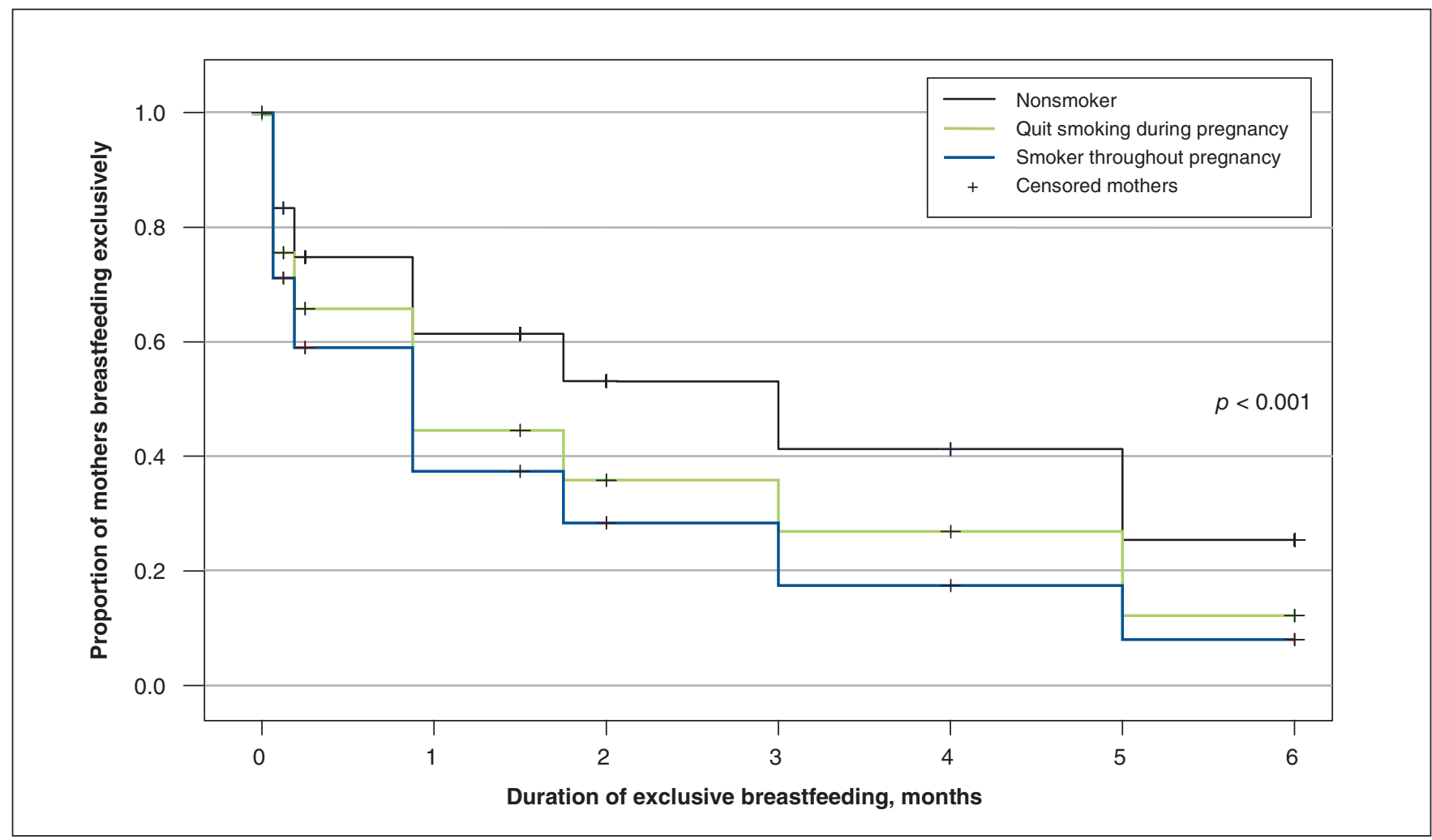

Figure 3: Kaplan-Meier curves of duration of exclusive breastfeeding in first 6 months after birth among 2907 mothers who initiated breastfeeding stratified by maternal smoking status. (See Figure 2 for the total number of women censored at each point.)

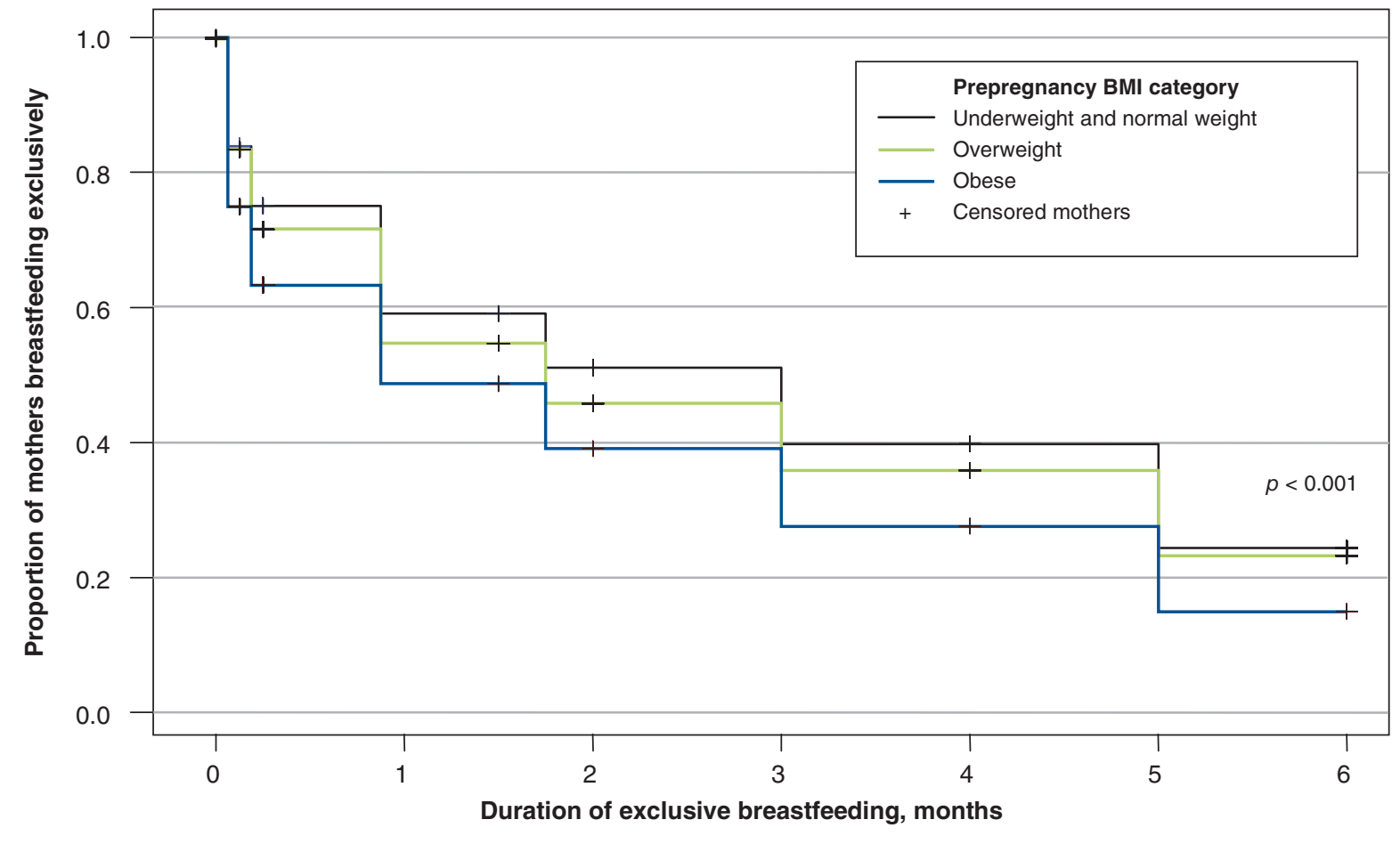

Figure 4: Kaplan-Meier curves of duration of exclusive breastfeeding in first 6 months after birth among 2907 mothers who initiated breastfeeding, stratified by category of prepregnancy body mass index (BMI). (See Figure 2 for the total number of women censored at each point.) 
associations are likely a mix of causal and noncausal components. For instance, nicotine is known to increase dopamine secretion in the hypothalamus, which leads to reduced prolactin levels and may in turn decrease milk yield. ${ }^{23,24}$ At the same time, mothers who smoke may be less health conscious and thus less motivated to breastfeed exclusively. ${ }^{25}$ Similar to the effect of smoking, adipose tissue may inhibit the prolactin response, compromising an obese woman's ability to produce milk; in addition, obese women encounter more sociocultural and psychological barriers to breastfeeding. ${ }^{26-28}$ Although obese women and normal-weight women in our study had similar rates of breastfeeding initiation, obese mothers were significantly more likely to have stopped exclusive breastfeeding by 6 months (Table 3 ). This difference suggests a potential physiologic explanation for early cessation of exclusive breastfeeding among obese women. Beyond delayed lactogenesis, obese women may also have practical difficulties with their infant achieving a proper latch, and they are at increased risk of other medical conditions such as diabetes and polycystic ovary syndrome. ${ }^{28}$ For both smoking and obesity, it is recognized that social factors, physical difficulties and physiologic explanations may contribute to the observed associations.

\section{Limitations}

Our study has limitations. First, although we were able to capture all births in a defined geographic region and period, our cohort may have limited generalizability to larger Canadian urban centres that have a high proportion of visible minorities. The largest city in the study region was Cape Breton Regional Municipality, with a population of about 100000.

Second, we did not have information on race or ethnicity. However, data from the 2006 census determined that less than $2 \%$ of the population in the 2 study districts are visible minorities. ${ }^{13}$ Indeed, compared with the Canadian sample in the Maternity Experiences Survey, our study cohort had a younger age distribution, a lower educational status, a higher proportion of single mothers, a higher proportion of mothers who were smokers and a higher proportion of mothers who were overweight or obese. ${ }^{5}$

Third, breastfeeding information obtained at each followup assessment was self-reported. This was similar to methods used in previous national cross-sectional surveys conducted by telephone, such as the Maternity Experiences Survey. Although breastfeeding status was collected prospectively at 5 follow-up assessments, a larger number of assessments or a measure of the exact length of breastfeeding duration would have increased the study's precision.

Fourth, the scope of the population-based databases was limited by their lack of data on important breastfeeding predictors, such as mother's ethnicity, breastfeeding self-efficacy, breastfeeding difficulties, support, postpartum employment and workplace policies. Future studies on breastfeeding would benefit from inclusion of predictors suggested by the BabyFriendly Hospital Initiative, ${ }^{21}$ including use of pacifiers and strength of postpartum maternal support.

Fifth, the creation of a dummy "missing" category is not an ideal way to treat missing covariates, because it tends to underestimate uncertainty in some analyses where sample size is inflated, while overestimating uncertainty in other analyses because the degrees of freedom is increased. ${ }^{29}$ In our study, however, a complete-case analysis would have resulted in a high risk of selection bias, because many mothers had at least one missing covariate.

Finally, midpoint imputation offers a good approximation when the period between follow-up observations is short and the data were not skewed. ${ }^{30,31}$ Although the first condition was met in our study, the duration of exclusive breastfeeding was positively skewed, so midpoint imputation may have overestimated the duration of exclusive breastfeeding slightly.

\section{Conclusion}

Our findings suggest that additional support for mothers and their newborns, particularly within the first 6 weeks of life, is critical to close the gap between breastfeeding recommendations and practices. We found that most of the predictors of early cessation of breastfeeding were intertwined with social determinants of health: mothers were less likely to breastfeed and less likely to do so exclusively if they were poorly educated, without a partner and not wealthy. These factors are not likely to change in the population in the short term. However, we did identify potentially modifiable factors. Providing opportunities for early breast contact by the infant as part of routine postpartum care, and continued efforts in smoking cessation and obesity reduction may contribute to longer durations of exclusive breastfeeding.

\section{References}

1. World Health Organization. The optimal duration of exclusive breastfeeding: report of an expert consultation. Geneva (Switzerland): the Organization; 2001 Available: www.who.int/nutrition/publications/optimal_duration_of_exc_bfeeding _report_eng.pdf (accessed 2010 Nov. 26).

2. World Health Organization. Global strategy for infant and young child feeding. Geneva (Switzerland): the Organization; 2003. Available: www.paho.org /english/ad/fch/ca/GSIYCF_infantfeeding_eng.pdf (accessed 2010 Nov. 26).

3. 55th World Health Assembly. Infant and young child nutrition. Geneva (Switzerland) the Assembly; 2002. Available: http://apps.who.int/gb/archive/pdf_files/WHA55 /ewha5525.pdf (accessed 2010 Nov. 26).

4. Exclusive breastfeeding duration. Ottawa (ON): Health Canada; 2004. Available: http://publications.gc.ca/collections/Collection/H44-73-2004E.pdf (accessed 2012 Nov. 23).

5. What mothers say: the Canadian Maternity Experiences Survey. Ottawa (ON) Public Health Agency of Canada; 2009. Available: www.phac-aspc.gc.ca/rhs-ssg /pdf/survey-eng.pdf (accessed 2010 Nov. 30).

6. Leon-Cava N, Lutter C, Ross J, et al. Economic benefits of breastfeeding. In: Quantifying the benefits of breastfeeding: a summary of the evidence. Washington (DC): Pan American Health Organization; 2002. Available: www.paho.org /english/ad/fch/BOB6.pdf (accessed 2012 Oct. 11).

7. Simard I, O'Brien HT, Beaudoin A, et al. Factors influencing the initiation and duration of breastfeeding among low-income women followed by the Canada Prenatal Nutrition Program in 4 regions of Quebec. 7 Hum Lact 2005;21:327-37.

8. Clifford TJ, Campbell MK, Speechley KN, et al. Factors influencing full breastfeeding in a southwestern Ontario community: assessments at 1 week and at 6 months postpartum. 7 Hum Lact 2006;22:292-304.

9. Semenic S, Loiselle C, Gottlieb L. Predictors of the duration of exclusive breastfeeding among first-time mothers. Res Nurs Health 2008;31:428-41.

10. Kehler HL, Chaput KH, Tough SC. Risk factors for cessation of breastfeeding prior to six months postpartum among a community sample of women in Calgary, Alberta. Can 7 Public Health 2009;100:376-80.

11. Joseph KS, Fahey J; Canadian Perinatal Surveillance System. Validation of perinatal data in discharge abstract database of the Canadian Institute for Health Information. Chronic Dis Can 2009;29:96-100.

12. Fair M, Cyr M, Allen AC, et al.; Fetal and Infant Health Study Group. An assessment of the validity of a computer system for probabilistic record linkage of birth and infant death records in Canada. Chronic Dis Can 2000;21:8-13.

13. Nova Scotia community counts. Halifax (NS): Government of Nova Scotia; 2012 
Available: www.gov.ns.ca/finance/communitycounts/default.asp (accessed 2012 Feb. 6).

14. Labbok M, Krasovec K. Toward consistency in breastfeeding definitions. Stud Fam Plann 1990;21:226-30.

15. Millar W, Maclean H. Breastfeeding practices. Health Rep 2005;16:23-30.

16. Al-Sahab B, Lanes A, Feldman M, et al. Prevalence and predictors of 6-month exclusive breastfeeding among Canadian women: a national survey. BMC Pediatr 2010;10:20.

17. Trends in breastfeeding practices in Canada (2001 to 2009-2010). Ottawa (ON): Health Canada; 2012. Available: www.hc-sc.gc.ca/fn-an/surveill/nutrition /commun/prenatal/trends-tendances-eng.php (accessed 2012 Oct. 11).

18. Institute of Medicine and National Research Council. Weight gain during pregnancy: reexamining the guidelines. Washington (DC): The National Academies Press; 2009.

19. The Canadian guidelines for body weight classification in adults. Ottawa (ON): Health Canada; 2003.

20. Meedya S, Fahy K, Kable A. Factors that positively influence breastfeeding duration to 6 months: a literature review. Women Birth 2010;23:135-45.

21. Breastfeeding Committee for Canada. Breastfeeding Committee for Canada integrated ten steps \& $W H O$ code practice outcome indicators for hospitals and community health services: summary. Drayton Valley (AB): the Committee; 2011. Available: http://breastfeedingcanada.ca/documents/2011-03-30_BCC_BFI_Integrated_10 _Steps_summary.pdf (accessed 2012 Mar. 26).

22. Kramer MS, Chalmers B, Hodnett ED, et al. Promotion of Breastfeeding Intervention Trial (PROBIT): a randomized trial in the Republic of Belarus. 7AMA 2001;285:413-20.

23. Amir LH. Maternal smoking and reduced duration of breastfeeding: a review of possible mechanisms. Early Hum Dev 2001;64:45-67.

24. Amir LH, Donath SM. Does maternal smoking have a negative physiological effect on breastfeeding? The epidemiological evidence. Birth 2002;29:112-23.

25. Donath SM, Amir LH; ALSPAC Study Team. The relationship between maternal smoking and breastfeeding duration after adjustment for maternal infant feeding intention. Acta Paediatr 2004;93:1514-8.

26. Oddy WH, Li J, Landsborough L, et al. The association of maternal overweight and obesity with breastfeeding duration. 7 Pediatr 2006;149:185-91.

27. Rasmussen KM, Kjolhede CL. Prepregnant overweight and obesity diminish the prolactin response to suckling in the first week postpartum. Pediatrics 2004; 113:e465-71.

28. Amir LH, Donath S. A systematic review of maternal obesity and breastfeeding intention, initiation and duration. BMC Pregnancy Childbirth 2007;7:9.

29. Greenland S, Finkle WD. A critical look at methods for handling missing covari- ates in epidemiologic regression analyses. Am 7 Epidemiol 1995;142:1255-64 .

30. Law CG, Brookmeyer R. Effects of mid-point imputation on the analysis of doubly censored data. Stat Med 1992;11:1569-78.

31. Hewett P, Ganser GH. A comparison of several methods for analyzing censored data. Ann Occup Hyg 2007;51:611-32.

Affiliations: From the Department of Community Health and Epidemiology (Brown, Dodds, Flowerdew, Langille), Dalhousie University, Halifax, NS; the Departments of Obstetrics and Gynecology and of Pediatrics (Dodds), Dalhousie University, Halifax, NS; the Reproductive Care Program of Nova Scotia (Attenborough, Rose, Lauzon), Halifax, NS; the School of Nursing (Bryanton), University of Prince Edward Island, Charlottetown, PEI; and the School of Nursing (Semenic), McGill University, Montréal, Que.

Contributors: Linda Dodds, Janet Bryanton and Sonia Semenic conceived the project and developed the study protocol. Catherine Brown, Gordon Flowerdew and Donald Langille contributed to the development of the analysis plan and, along with Linda Dodds, the analysis of the data. Rebecca Attenborough, Annette Elliott Rose and Leeanne Lauzon contributed expertise in breastfeeding patterns in Nova Scotia and assisted in development of the study protocol and interpretation of the data. Catherine Brown and Linda Dodds wrote the first draft of the manuscript, and all of the authors assisted in revising it. All of the authors approved the final version submitted for publication.

Funding: This study was funded by the Nova Scotia Health Research Foundation. Catherine Brown received a graduate student scholarship from the IWK Health Centre.

Acknowledgements: The authors thank the Reproductive Care Program of Nova Scotia and the Public Health Services in Cape Breton District Health Authority and Guysborough Antigonish Strait Health Authority for providing access to the data. They also thank Dr. Colleen O'Connell for technical support.

Supplemental information: For reviewer comments and the original submission of this manuscript, please see at www.cmajopen.ca/content /1/1/E9/suppl/DC1 